Article

\title{
The Dual Immunoregulatory function of Nlrp12 in T Cell-Mediated Immune Response: Lessons from Experimental Autoimmune Encephalomyelitis
}

\author{
Marjan Gharagozloo, Shaimaa Mahmoud, Camille Simard, Tara M. Mahvelati ${ }^{\mathbb{D}}$, \\ Abdelaziz Amrani and Denis Gris * (D) \\ Program of Immunology, Department of Pediatrics, CR-CHUS, Faculty of Medicine and Health Sciences, \\ University of Sherbrooke, Sherbrooke, QC J1H 5N4, Canada; Marjan.Gharagozloo@usherbrooke.ca (M.G.); \\ Shaimaa.Mahmoud@usherbrooke.ca (S.M.); Camille.Simard@usherbrooke.ca (C.S.); \\ t.mahvelati@gmail.com (T.M.M.); Abdelaziz.Amrani@usherbrooke.ca (A.A.) \\ * Correspondence: denis.gris@usherbrooke.ca; Tel.: +819-346-1110 (ext. 16632)
}

Received: 3 August 2018; Accepted: 23 August 2018; Published: 27 August 2018

\begin{abstract}
Although the etiology of multiple sclerosis (MS) remains enigmatic, the role of T cells is unquestionably central in this pathology. Immune cells respond to pathogens and danger signals via pattern-recognition receptors (PRR). Several reports implicate Nlrp12, an intracellular PRR, in the development of a mouse MS-like disease, called Experimental Autoimmune Encephalomyelitis (EAE). In this study, we used induced and spontaneous models of EAE, as well as in vitro T cell assays, to test the hypothesis that Nlrp12 inhibits Th1 response and prevents T-cell mediated autoimmunity. We found that Nlrp12 plays a protective role in induced EAE by reducing IFN $\gamma /$ IL-4 ratio in lymph nodes, whereas it potentiates the development of spontaneous EAE (spEAE) in 2D2 T cell receptor (TCR) transgenic mice. Looking into the mechanism of Nlrp12 activity in T cell response, we found that it inhibits $\mathrm{T}$ cell proliferation and suppresses Th1 response by reducing IFN $\gamma$ and IL-2 production. Following TCR activation, Nlrp12 inhibits Akt and NF-KB phosphorylation, while it has no effect on $\mathrm{S} 6$ phosphorylation in the mTOR pathway. In conclusion, we propose a model that can explain the dual immunoregulatory function of Nlrp12 in EAE. We also propose a model explaining the molecular mechanism of Nlrp12-dependent regulation of $\mathrm{T}$ cell response.
\end{abstract}

Keywords: Nlrp12; CNS; inflammation; T cell; EAE; spontaneous EAE; TCR signaling; 2D2

\section{Introduction}

Multiple sclerosis (MS) is a chronic autoimmune disease of the central nervous system (CNS), where autoreactive immune responses are involved in demyelination and CNS damage. The etiology and pathogenesis of the disease remain elusive. However, several lines of evidence demonstrate that adaptive immune response plays a key role in the pathogenesis of MS and experimental autoimmune encephalomyelitis (EAE), the mouse model of MS [1-3]. The major components of the adaptive immunity, T cells, are initially activated by antigen presenting cells (APCs) in lymph nodes. Activated $\mathrm{T}$ cells migrate into the CNS across the blood brain barrier (BBB) and reactivated again in perivascular space, where CNS-resident cells including microglia and macrophages present myelin antigens to $\mathrm{T}$ cells [4]. Thus, those activated $\mathrm{CD} 4^{+} \mathrm{T}$ cells orchestrate the functions of other adaptive immune cells, such as $\mathrm{CD} 8^{+} \mathrm{T}$ cells and B cells, as well as innate immune cells in the CNS and periphery [5]. Depending on the composition of the cytokine milieu, naïve $\mathrm{CD} 4^{+} \mathrm{T}$ cells may differentiate into different Thelper (Th) subsets including Th1, Th2 and Th17 that produce signature cytokines such as IFN $\gamma$, IL-4 and IL-17 respectively. The differentiation of naïve CD4 ${ }^{+} \mathrm{T}$ cells into Th1, Th2, or Th17 
types are governed by transcription factors, known as Tbet, GATA3 and ROR $\gamma \mathrm{t}$ respectively [6]. Th subsets affect the CNS inflammation in different ways. Th1 and Th17 responses potentiate the CNS inflammation, while Th2 response dampens inflammatory response and protects CNS damage [6]. These findings highlight the importance of T cell-mediated immunity in MS pathology.

APCs including dendritic cells, macrophages and microglia are innate immune cells that trigger $\mathrm{T}$ cell activation [7]. These cells create the first line of response by recognizing pathogens and/or danger signals via pattern-recognition receptors (PRR) [8]. NOD-like receptors (NLRs) are intracellular PRR that are mainly expressed by cells of hematopoietic origin and regulate both innate and adaptive immune responses [9]. Recently, NLRs have gained more attention since 3 members of the family including CIITA, Nlrc5 and Nlrp3 regulate transcription of molecules that shape adaptive immune responses. CIITA [10] and Nlrc5 [11,12] show transcriptional activities for MHC II and MHC I molecules respectively, while Nlrp3 acts as a Th2 transcription factor and promotes IL-4 production [13]. In addition, activation of NLRs often leads to the production and secretion of pro-inflammatory cytokines such as IL-1 $\beta$ and IL-18 that in turn potentiate differentiation of Th1 and Th17 subsets $[9,14]$. These findings highlight the key role of NLR proteins in shaping $\mathrm{T}$ cell response and adaptive immunity.

Not all NLRs are pro-inflammatory. Nlrp12 is a recently discovered member of NLRs that is shown to be a negative regulator of both canonical and non-canonical nuclear factor- $\mathrm{kB}$ (NF- $\mathrm{kB}$ ) signaling pathways [15]. Previous studies showed that $\mathrm{Nlrp} 12^{-/-}$mice are highly vulnerable to inflammatory diseases such as experimental colitis and colorectal tumor development [16-19]. In the context of CNS inflammation, the lack of Nlrp12 resulted in increased CNS inflammation and exacerbated course of EAE [19]. Nlrp12-/- mice developed earlier and more severe form of EAE than wild-type (WT) mice. This phenotype parallel with significant increases in the expression of pro-inflammatory genes in the spinal cords of Nlrp12-/- mice relative to WT mice. Experiments using mouse primary microglia cultures demonstrated that Nlrp12 significantly inhibits production of the inflammatory mediators such as inducible nitric oxide synthase (iNOS), Tumor Necrosis Factor (TNF) $\alpha$, IL- 6 and nitric oxide (NO) [19]. However, the ability of Nlrp12 to modulate T cell responses remains poorly defined.

A recent article by Lukens et al. revealed that Nlrp12 is expressed not only by myeloid cells but also by $\mathrm{T}$ cells. It negatively regulates NF- $\mathrm{kB}$ signaling, $\mathrm{T}$ cells proliferation and the secretion of Th1/Th2/Th17 cytokines [20]. Non-surprisingly, Nlrp12 deficient mice developed enhanced inflammatory symptoms in T-cell-mediated autoimmune diseases such as colitis and atopic dermatitis [20]. However, in EAE model, lack of Nlrp12 promotes Th2 response and IL-4 secretion, which results in a milder form of EAE with atypical symptoms, including ataxia and impaired balance control [20]. Collectively, current findings and controversies indicate that the exact immunoregulatory functions of Nlrp12 in T cell activation and T cell-mediated autoimmunity are poorly understood.

In this study, we investigated the immunoregulatory role of Nlrp12 in T cell responses using classical induced-EAE and spontaneous EAE (spEAE) models. We further characterized the role of Nlrp12 in regulating T cell receptor (TCR) signaling pathways and IL-2 production.

\section{Materials and methods}

\subsection{Mice}

All the protocols and procedures were approved by the University of Sherbrooke Animal Facility and Use Committee (Protocols \#280-15, 4 April 2017; \#335-17B, 22 February 2018). Nlrp12 knock-out (Nlrp12-/-) mice on C57BL/6J background were kindly provided by Dr. Jenny P.Y. Ting (Chapel Hill, NC, USA). Mice were backcrossed for at least 15 generation. The 2D2 transgenic mice expressing a TCR specific for the myelin oligodendrocyte $\left(\mathrm{MOG}_{35-55}\right)$ peptide were purchased from Jackson Laboratory. Nlrp $12^{-/-}$and WT mice were crossed with 2D2 mice to generate Nlrp12-/- $2 \mathrm{D} 2$ mice. We genotyped all the animals for Nlrp12 and 2D2 (Supplementary protocol) and only those animals that were Nlrp $12^{-/-}$and $2 \mathrm{D} 2^{+}$were included in the study (Supplementary Figure S1). Moreover, the expression of $\mathrm{V} \beta 11$ receptor was verified with flow cytometry. The mice were maintained under 
specific pathogen-free conditions in the animal facility of the faculty of medicine, at the University of Sherbrooke.

\subsection{Induction of EAE and Tissue Collection}

EAE was induced in 8-10-week old WT or Nlrp12-/- female mice as previously described [19]. An emulsion mixture of $\mathrm{MOG}_{35-55}$ (Genemed Synthesis Inc., San Antonio, TX, USA), complete Freund's Adjuvant (CFA) (Sigma-Aldrich, St. Louis, MO, USA) and Mycobacterium tuberculosis H37 RA (Difco Laboratories, Detroit, MI, USA) was prepared and injected subcutaneously in the flank with a total of $200 \mu \mathrm{g} \mathrm{MOG}_{35-55}$ and $500 \mu \mathrm{g}$ Mycobacterium. Mice were also injected intraperitoneally on days 0 and 2 with $200 \mathrm{ng}$ Pertussis toxin (List Biological Laboratories Inc., Campbell, CA, USA). After 3 weeks of immunization, mice were sacrificed, perfused with ice-cold phosphate-buffered saline (PBS) (Wisent, St. Bruno, QC, Canada) and the CNS tissues were collected.

\subsection{Intracellular Staining and Flow Cytometry}

$\mathrm{CD}^{+} \mathrm{T}$ cells were purified from lymph nodes and spleens using Mouse $\mathrm{CD} 4^{+} \mathrm{T}$ Cell Isolation Kit (eBioscience, San Diego, CA, USA) and activated with plate-bound anti-CD3 (eBioscience, clone:145-2C11, $1 \mu \mathrm{g} / \mathrm{mL}$ ) and anti-CD28 (eBioscience, clone: 37.51, $2 \mu \mathrm{g} / \mathrm{mL}$ ) antibodies for indicated times. T cell proliferation was assessed by Ki67 intranuclear staining following fixation and permeabilization in the Foxp3/Transcription Factor staining kit (eBioscience). For intracellular staining of cytokines, the cells were stimulated with phorbol 12-myristate 13-acetate (PMA; $500 \mathrm{ng} / \mathrm{mL}$, Sigma Chemical Co., St. Louis, MO, USA) and ionomycin $(1 \mu \mathrm{g} / \mathrm{mL}$, Calbiochem Corp., La Jolla, CA, USA) for $5 \mathrm{~h}$ at $37^{\circ} \mathrm{C}$ in the presence of Brefeldin A (10 $\mu \mathrm{g} / \mathrm{mL}$, eBioscience). Cells were stained with anti-CD4-FITC antibody (eBioscience), fixed, permeabilized and then stained with anti-IFN $\gamma$-PE, anti-IL-4-PE, IL-17-PerCP-Cy5.5, Tbet-PE, or ROR $\gamma$ t-PE antibody, as per the manufacturer's instructions (eBioscience). Sample acquisition was performed with Beckman Coulter CytoFlex (Beckman Coulter, Brea, CA, USA) and data were analyzed using CytExpert 2 software (Beckman Coulter, Brea, CA, USA). Plots were prepared using CytExpert 2 and FlowJo (San Carlos, CA, USA) software.

\subsection{Quantitative RT-PCR}

RNA was extracted from $\mathrm{CD}^{+}{ }^{\mathrm{T}}$ cells using TRIzol reagent (Life Technologies Inc., Burlington, ON, USA) and cDNA was synthesized as previously described [19]. Reverse transcription PCR (RT-PCR) was used to verify the expression of Nlrp12 in activated T cell using KiCqStart $^{\mathrm{TM}} \mathrm{SYBR}^{\circledR}$ Green qPCR ReadyMix (Sigma Aldrich, St. Louis, MO, USA). Primers (IDT, Coralville, IA, USA) sequences were as follows: Nlrp12F: 5'-CCT CTT TGA GCC AGA CGA AG-3', Nlrp12R: 5'-GCC CAG TCC AAC ATC ACT TT-3', 18SF: 5'-CGG CTA CCA CAT CCA AGG AA-3' and 18SR: $5^{\prime}$-GCT GGA ATT ACC GCG GCT-3'. The relative expression was calculated using the $\Delta \Delta C_{\mathrm{T}}$ method [21].

\subsection{Cytokine Measurement}

IFN $\gamma$ and IL- 4 cytokines in the supernatant of activated CD4 ${ }^{+} \mathrm{T}$ cell culture and tissue lysates were measured using ELISA kits as previously described [19]. Briefly, lymph node, spinal cord and cerebellum tissues were homogenized in lysis buffer supplemented with protease inhibitors (Cell Signaling Technology, Danvers, MA, USA) by rapid agitation using 3-mm stainless beads and a TissueLyser II (Qiagen, Hilden, Germany) homogenizer for $2 \mathrm{~min}$. The levels of IL-4 in tissue lysates were determined using a high sensitivity IL-4 ELISA Kit (eBioscience, San Diego, CA, USA) according to the manufacturer's instruction. The amount of IFN $\gamma$ was determined using IFN $\gamma$ kit purchased from PeproTech (Rocky Hill, NJ, USA). 


\subsection{Differentiation of 2D2 T Cells Toward Th1 or Th17 In Vitro}

Naïve $\mathrm{CD} 4^{+} \mathrm{T}$ cells were purified from the spleens and lymph nodes of Nlrp12-/- $2 \mathrm{D} 2$ and WT 2D2 mice using MagniSort Naïve CD4 T Cell Enrichment Kit (eBiosciences). Purified CD4 ${ }^{+} \mathrm{T}$ cells were stimulated with MOG $(50 \mu \mathrm{g} / \mathrm{mL})$ in the presence of WT splenocytes at 1:1 ratio and Th1-, Th2- or Th17- polarizing condition (Th1: IL-12 (10 ng/mL), anti-IL-4 (10 $\mu \mathrm{g} / \mathrm{mL})$, IL-2 (10 ng/mL); Th2: IL-4 $(10 \mu \mathrm{g} / \mathrm{mL})$, hTGF- $\beta 1$ (10 ng/mL), IL-2 $(10 \mathrm{ng} / \mathrm{mL})$ and Th17: anti-IL-12 $(10 \mu \mathrm{g} / \mathrm{mL})$, anti-IL-4 $(10 \mu \mathrm{g} / \mathrm{mL})$, anti-IFN- $\gamma(10 \mu \mathrm{g} / \mathrm{mL}), \mathrm{mIL}-6(10 \mathrm{ng} / \mathrm{mL})$, hTGF- $\beta 1(10 \mathrm{ng} / \mathrm{mL}))$. Recombinant cytokines and antibodies were purchased from Biolegend (San Diego, CA, USA) and eBioscience (San Diego, CA, USA), respectively. After $72 \mathrm{~h}$ of culture, cells were stained for MOG-TCR transgenic surface marker, V $\beta 11$ and Th1- or Th17- associated markers (intracellular cytokine and transcription factor). The percentage of Th1 or Th17 cells were evaluated by Flow cytometry.

\subsection{T Cell Activation and Signaling Pathways}

To analyze p65 phosphorylation upon CD3 cross-linking, $\mathrm{CD}^{+} \mathrm{T}$ cells were purified from the lymph nodes of Nlrp12-/- and WT mice and incubated with $10 \mu \mathrm{g} / \mathrm{mL}$ anti-CD3 (eBioscience, San Diego, CA, USA) for $30 \mathrm{~min}$ on ice, followed by washing and re-suspending the cells in serum-free medium. T cells were incubated with $10 \mu \mathrm{g} / \mathrm{mL}$ cross-linking anti-mouse IgG antibody (R\&D systems, Minneapolis, MN, USA) for $20 \mathrm{~min}$ at $37^{\circ} \mathrm{C}$. Akt phosphorylation was quantified after activation of $\mathrm{CD} 4^{+} \mathrm{T}$ cells with PMA/Iono for $10 \mathrm{~min}$ at $37^{\circ} \mathrm{C}$, while the phosphorylation of $\mathrm{S} 6$ was analyzed after $24 \mathrm{~h}$ activation of $\mathrm{CD} 4^{+} \mathrm{T}$ cells with plate-bound anti-CD3/CD28 antibodies. Following stimulation in a defined period of time, $\mathrm{T}$ cells were washed and lysed in the lysis buffer plus proteinase and phosphatase inhibitor (Cell Signaling Technology). Proteins were then separated by on $10 \%$ SDS-polyacrylamide gels and transferred to nitrocellulose membrane. Transfers were blocked for $1 \mathrm{~h}$ at room temperature with 5\% nonfat milk in TBS/0.1\% Tween 20 (TBST) and then incubated overnight at $4{ }^{\circ} \mathrm{C}$ in the primary antibodies (Cell Signaling Technology) diluted in TBST. The membranes were washed 3 times with TBST and incubated in horseradish peroxidase (HRP)-conjugated goat anti-rabbit antibody (Cell Signaling Technology) diluted 1/1000 in TBST for $1 \mathrm{~h}$ at room temperature. The immunoblots were developed with Lumigen ECL ultra reagent (Lumigen, Southfield, MI, USA), imaged with ChemiDoc $^{\mathrm{TM}}$ (Bio-Rad, Hercules, CA, USA) and analyzed using Image Lab software (Bio-Rad).

\subsection{Phosphoflow Cytometry}

Phosphorylation of S6 ribosomal protein was confirmed by flow cytometry. Following $24 \mathrm{~h}$ stimulation of $\mathrm{CD}^{+} \mathrm{T}$ cells with plate-bound anti-CD3/CD28, cells were immediately fixed and permeabilized using Fix and Perm Kit (eBioscience). After washing with perm buffer (eBioscience) and blocking with 5\% Fetal Bovine Serum, cells were incubated with Phospho-S6 antibody (Cell Signaling Technology) for $1 \mathrm{~h}$ at room temperature, followed by washing with perm buffer and incubation with Alexa Fluor ${ }^{\circledR} 555$ (Cell Signaling Technology) conjugated antibody. Samples were acquired by Beckman Coulter CytoFlex and data was analyzed using CytExpert 2 software (Beckman Coulter, Brea, CA, USA).

\subsection{SpEAE and Histological Analysis}

WT 2D2 or Nlrp12-/- 2D2 mice were monitored for the development of spEAE. Animals were sacrificed after 4 months of monitoring or after the development of EAE at the peak score of 4 . The immunized mice were sacrificed as described in Section 2.2 and the spinal cords were removed and fixed in $4 \%$ formaldehyde for $24 \mathrm{~h}$. The spinal cord tissues were embedded in paraffin and cut into $5-\mu \mathrm{m}$ sections and stained with hematoxylin and eosin (H\&E) stain and immunofluorescence for astrocyte marker (GFAP), microglia marker (Iba1) and myelin basic protein (MBP). All slides were 
scanned using a digital slide scanner NanoZoomer-XR C12000 (Hamamatsu Photonics, Hamamatsu, Japan) and viewed using NDPview2 software (Hamamatsu Photonics, Hamamatsu, Japan).

\subsection{Analysis of CNS-Infiltrating Mononuclear Cells by Flow Cytometry}

Dissected spinal cords were filtered through a $70 \mathrm{~mm}$ nylon sieve (BD Pharmingen, Becton Dickinson, Franklin Lakes, NJ, USA) with a syringe plunger to get a uniform tissue homogenate that was digested with collagenase D ( $2.5 \mathrm{mg} / \mathrm{mL}$, Roche Diagnostics, Risch-Rotkreuz, Switzerland) and DNase I ( $1 \mathrm{mg} / \mathrm{mL}$, Sigma-Aldrich) with agitation at $37^{\circ} \mathrm{C}$ for $45 \mathrm{~min}$. Mononuclear cells were isolated by percoll (Sigma-Aldrich) centrifugation, in which $300 \mu \mathrm{L}$ percoll was mixed with $1 \mathrm{~mL}$ cell suspension overlaid with $700 \mu \mathrm{L}$ Hank's Balanced Salt Solution (HBSS). The samples were centrifuged at $12,000 \times g$ for $15 \mathrm{~min}$ without break. Myelin and cell debris were aspirated and the mononuclear pellet was re-suspended and washed with HBSS before staining for surface markers and analysis by flow cytometry.

\subsection{Statistical Analysis}

All statistical analyses were conducted using GraphPad Prism 7 software (GraphPad, San Diego, CA, USA). Results were expressed as the mean \pm standard deviation. Statistical differences between WT and Nlrp12 ${ }^{-/-}$samples were assessed by Student's $t$-test. Level of Nlrp12 expression was assessed by one-way ANOVA and cellular signaling by two-way ANOVA. The significance level was set at $p<0.05$.

\section{Results}

\subsection{Nlrp12 Modulates Th1/Th2 Balance in EAE Mice}

Our previous study demonstrated that Nlrp $12^{-/-}$mice develop earlier and more severe EAE compared to WT mice (Supplementary Figure S2) [19]. Since Th1 cells play a crucial role in the pathogenesis of EAE, we examined whether the imbalance of Th1/Th2 response might lead to exacerbated EAE in Nlrp12 ${ }^{-/-}$mice. We collected lymph nodes and the CNS tissues including spinal cord and cerebellum from WT and Nlrp12-/- EAE mice at day 21 after MOG-CFA immunization and measured the level of IFN $\gamma$ and IL- 4 as the designated cytokines for Th1 and Th2 cells respectively. As shown in Figure 1, we found significantly higher levels of IFN $\gamma$ in lymph node extracts from Nlrp12-/EAE mice, while IL-4 levels were significantly lower than WT EAE mice. In addition, the ratio of IFN $\gamma /$ IL-4 was higher in lymph node extracts of Nlrp12-/- EAE mice, suggesting a higher Th1/Th2 ratio in Nlrp12-/- EAE (Figure 1A). No difference was observed in the levels of IFN $\gamma$ and IL-4 in the extracts of CNS tissues (spinal cord and cerebellum) (Figures 1B and 1C), however, IFN $\gamma / \mathrm{IL}-4$ ratio was significantly lower in spinal cords from Nlrp12-/- EAE mice compared to WT EAE mice (Figure 1B). We then evaluated the production of cytokines in ex vivo activated $\mathrm{CD}^{+} \mathrm{T}$ cells.

\subsection{Nlrp12 Inhibits the Production of IFN $\gamma$ by $\mathrm{CD}^{+} \mathrm{T}$ Cells In Vitro}

To determine whether Nlrp12 could inhibit IFN $\gamma$ production by T cells, we purified CD4 ${ }^{+} \mathrm{T}$ cells from WT and Nlrp12 $2^{-/}$mice and stimulated them with anti-CD3/CD28 antibodies to activate T cells with TCR and costimulatory signals simultaneously [22]. After $72 \mathrm{~h}$, cell culture supernatants were collected and the levels of IFN $\gamma$ and IL-4 were measured by ELISA. As shown in Figure 2A, activated $\mathrm{CD}^{+}{ }^{+} \mathrm{T}$ cells from Nlrp12 $2^{-1-}$ mice secreted significantly higher levels of IFN $\gamma$ and IL-4 compared to WT T cells. We then tested whether the increased levels of both Th1- and Th2-associated cytokines were related to the increased proliferation of Nlrp12 $2^{-/}$T cells compared to WT T cells. Ki67 is a nuclear protein that is expressed by the cells in all cell cycle phases except G0 phase [23]. Following activation by anti-CD3/CD28 antibody for $24 \mathrm{~h}$, the $\mathrm{CD} 4^{+} \mathrm{T}$ cells were stained for Ki67 and analyzed by flow cytometry. Results showed significantly higher numbers of Nlrp $12^{-/-} \mathrm{T}$ cells in the cell cycle compared to WT T cells (Figure 2B). Flow cytometric analysis of intracellular cytokines 
revealed that higher percentages of $\mathrm{CD}^{+} \mathrm{T}$ cells produced IFN $\gamma$ in $\mathrm{Nlrp} 12^{-/}$activated $\mathrm{T}$ cells. However, no significant difference was detected between Nlrp12-/- and WT T cells in the percentage of IL-4 or IL-17 producing T cells after 3 days of activation with anti-CD3/CD28 antibodies in vitro (Figure 2C). We then examined whether the exacerbated EAE in Nlrp12 $2^{-/}$mice was associated with the increased differentiation of myelin-specific T cells to Th1 or Th17 cells.

(A)
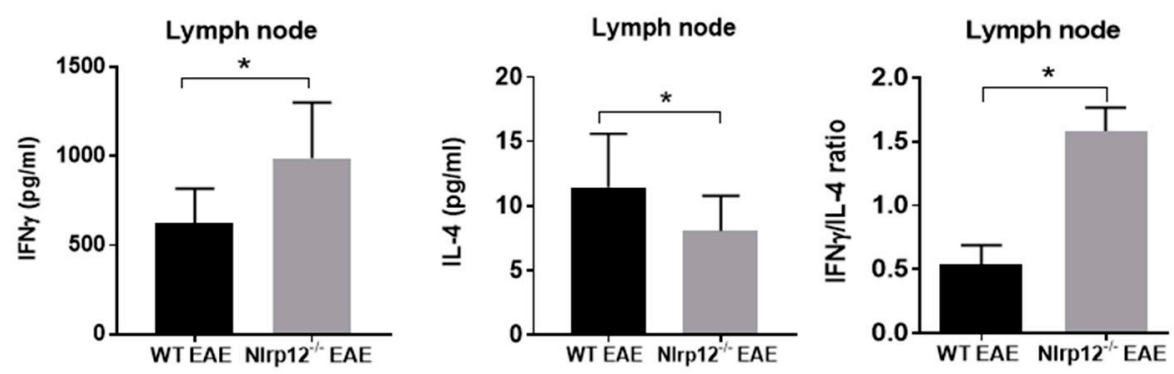

(B)
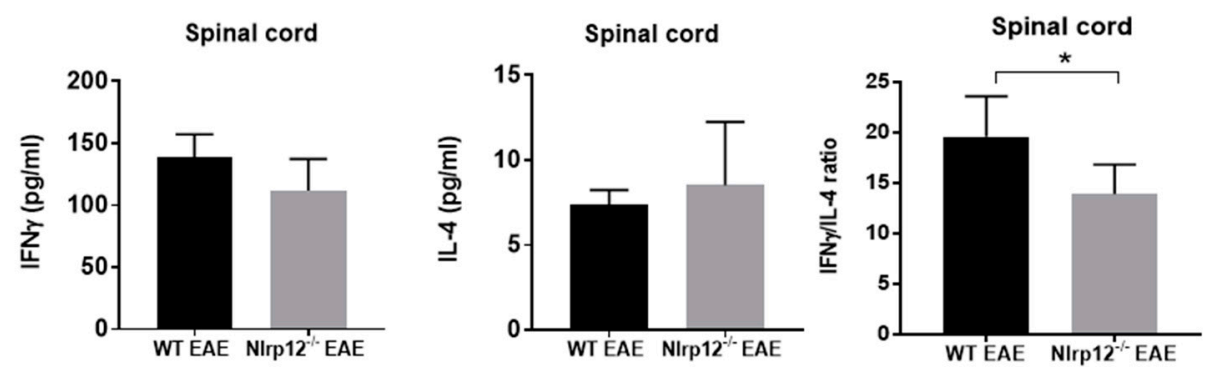

(C)
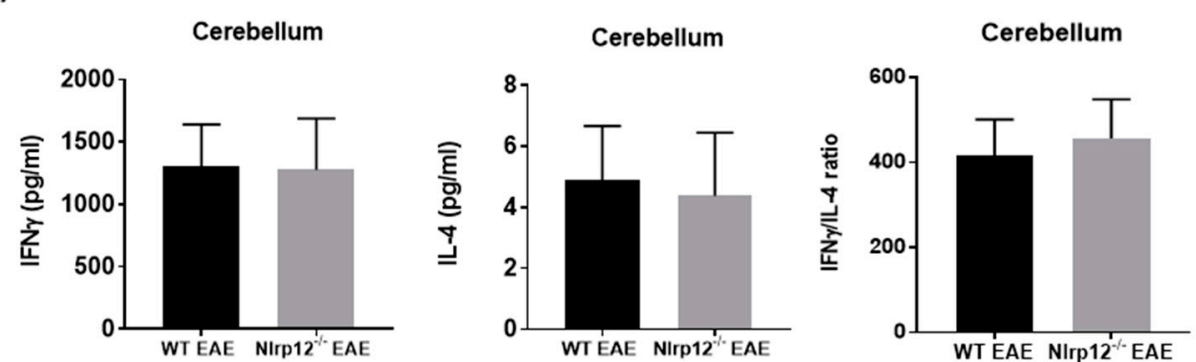

Figure 1. Nlrp12 inhibits Th1 response in Experimental Autoimmune Encephalomyelitis (EAE). Th1- and Th2- related cytokines in tissue lysates from EAE mice. Central nervous system (CNS) tissues and lymph nodes were collected from EAE mice after 3 weeks of immunization with myelin oligodendrocyte/complete Freund's adjuvant (MOG/CFA). The tissues were homogenized in lysis buffer and cytokine levels were measured in tissue lysate by ELISA. (A) The levels of IFN $\gamma$, IL-4 and IFN $\gamma /$ IL-4 ratio in lymph node extracts from WT and Nlrp12-/- EAE mice; (B) The levels of IFN $\gamma$, IL-4 and their ratios in the spinal cord and (C) cerebellum of EAE mice, $n=5-6$ per group, ${ }^{*} p<0.05$. 
(A)

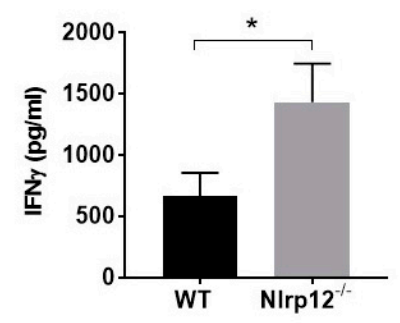

(C)
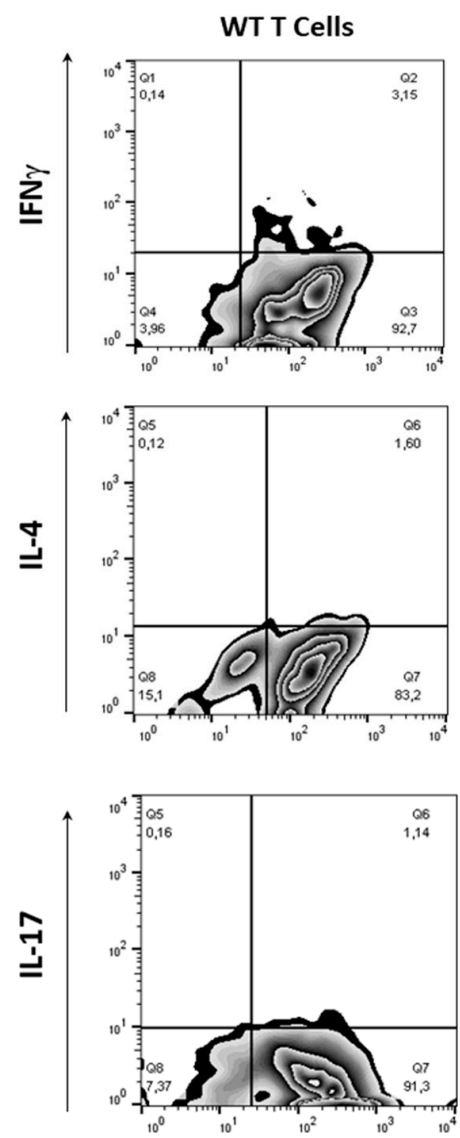

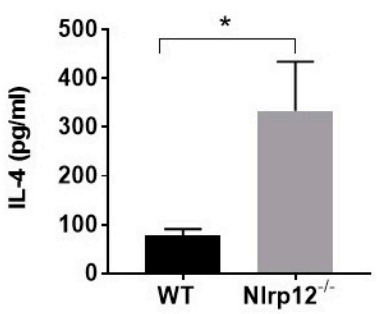

(B)

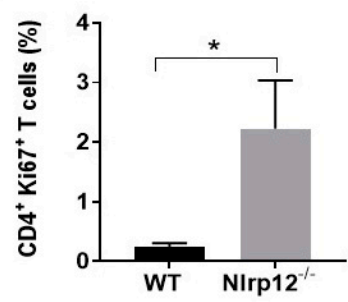

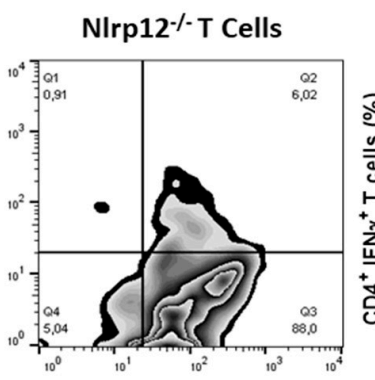
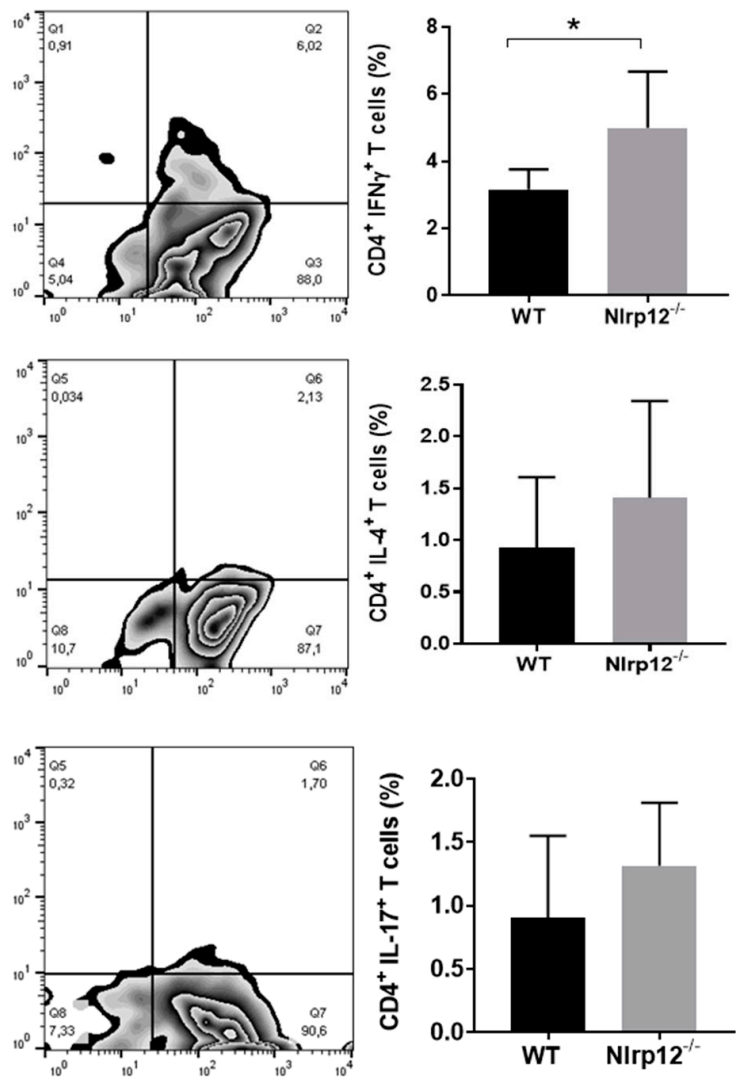

Figure 2. Nlrp12 inhibits $\mathrm{T}$ cell proliferation and cytokine production by $\mathrm{CD} 4^{+} \mathrm{T}$ cells. (A) Purified $\mathrm{CD}^{+} \mathrm{T}$ cells from WT and Nlrp12-/- mice were stimulated with anti-CD3/CD28 for $72 \mathrm{~h}$. Cell culture supernatants were collected and the levels of IFN $\gamma$ and IL- 4 were measured by ELISA, $n=4$; (B) Purified CD4 ${ }^{+} \mathrm{T}$ cells from WT and Nlrp12-/- mice were stimulated with anti-CD3/CD28 for $24 \mathrm{~h}$ and the proliferation of $\mathrm{CD} 4^{+} \mathrm{T}$ cells was evaluated using Ki67 staining and flow cytometry; (C) $\mathrm{CD} 4^{+}$ $\mathrm{T}$ cells were activated with anti-CD3/CD28 for $48 \mathrm{~h}$ and the expression of intracellular cytokines was measured using flow cytometry. Representative flow cytometric plots show the expression of IFN $\gamma$, IL-4 and IL-17 in CD4 ${ }^{+} \mathrm{T}$ cells, $n=4{ }^{*} p<0.05$.

\subsection{Nlrp12 Has No Effect on T Cell Differentiation toward Th1 and Th17}

We evaluated whether Nlrp12 would favor differentiation of naïve T cells towards inflammatory Th subsets. We purified naïve CD4 ${ }^{+} \mathrm{T}$ cells from lymph nodes and spleens of Nlrp12-/- $2 \mathrm{D} 2$ and WT 2D2 mice and cultured with MOG-pulsed WT splenocytes in the presence or absence of Th1 or Th17 polarizing cytokines. After $72 \mathrm{~h}$ of incubation, cells were harvested and stained for CD4 surface marker 
and Th1 (IFN $\gamma$ and Tbet) or Th17 (IL-17 and ROR $\gamma \mathrm{t}$ ) intracellular markers. Flow cytometry results show that Nlrp12 did not affect the differentiation of CD4 ${ }^{+}$T cells toward Th1 or Th17 (Figure 3).
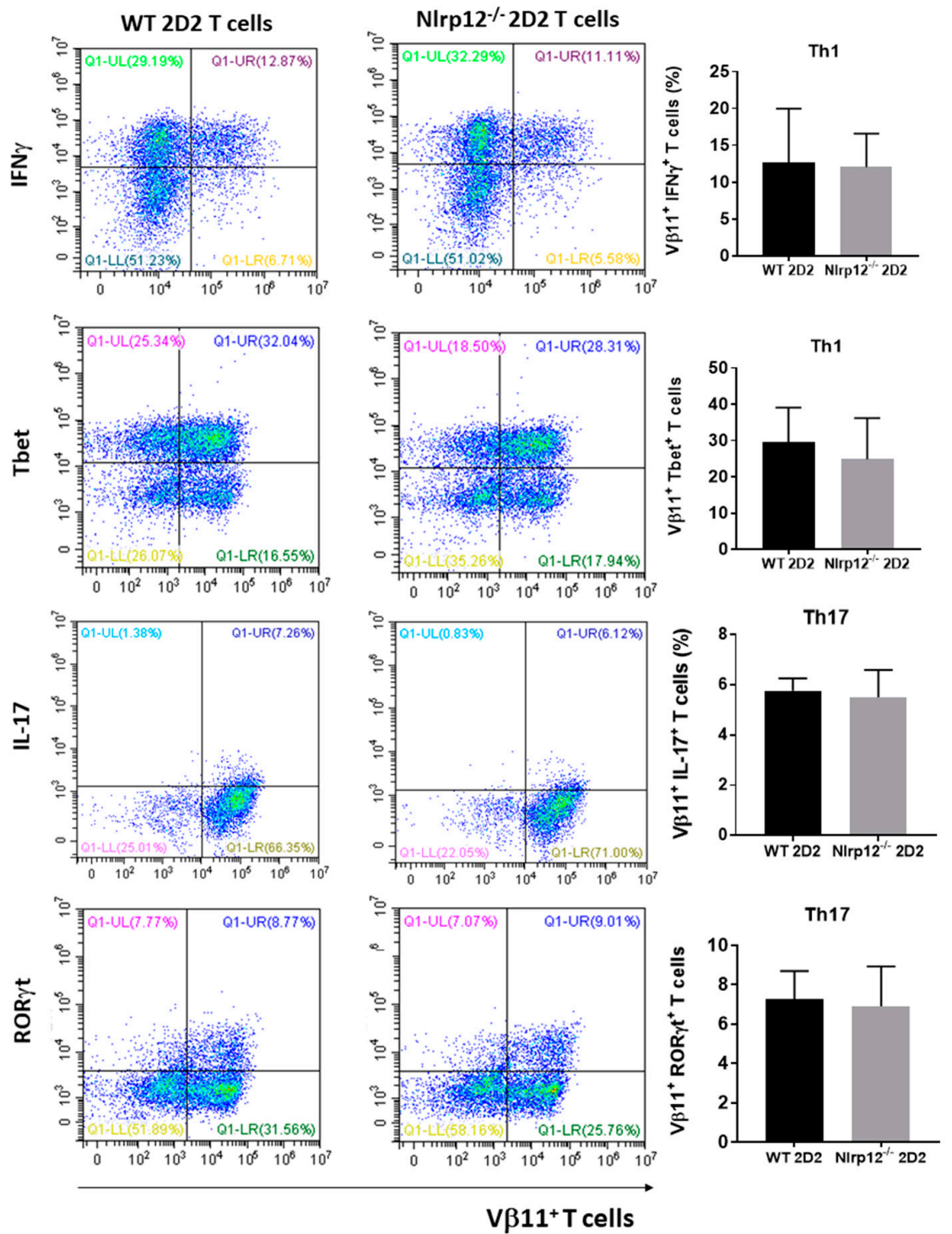

Figure 3. Nlrp12 does not affect the differentiation of naïve $\mathrm{CD} 4^{+} \mathrm{T}$ cells to Th1 or Th17. Naïve CD4 ${ }^{+} \mathrm{T}$ cells from WT and Nlrp12-/- mice were purified and stimulated with MOG-splenocytes in the presence of Th1 or Th17 polarizing cytokines for 3 days. After $5 \mathrm{~h}$ stimulation with PMA/ionomycin, cells were stained for V $\beta 11$ and Th1- or Th17- associated cytokine/transcription factor and analyzed by flow cytometry, $n=3$; Representative flow cytometric plots show the expression of Th1- and Th17-related markers in $\mathrm{V} \beta 11^{+} \mathrm{T}$ cells.

\subsection{Nlrp12 Expression Is Increased in Activated T Cells}

To test whether TCR activation modulated the expression of Nlrp12, we activated CD4 ${ }^{+} \mathrm{T}$ cells with either anti-CD3 or anti-CD3/CD28 antibodies for $24 \mathrm{~h}$ and measured the expression of Nlrp12 gene by qPCR. As shown in Figure 4A, the mRNA expression of Nlrp12 was significantly increased in T cells following activation by anti-CD3 or anti-CD3/CD28 antibodies. The level of Nlrp12 expression remains high even after $48 \mathrm{~h}$ stimulation of $\mathrm{T}$ cells by anti-CD3/CD28 (Figure $4 \mathrm{~B}$ ). Since we observed a change in Nlrp12 expression soon after T cell activation, we asked the question whether Nlrp12 could modify early TCR signaling events before commitment of T cells to a certain Th subset. 
(A)

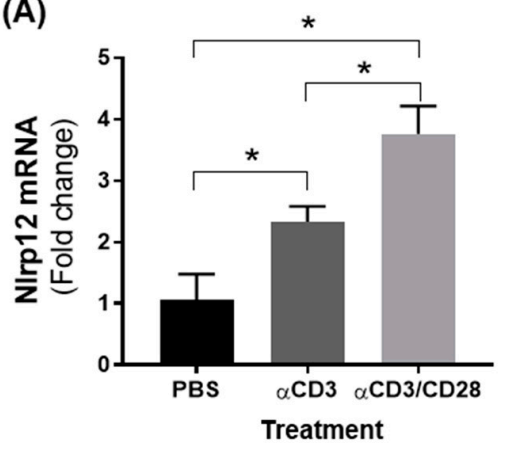

(B)

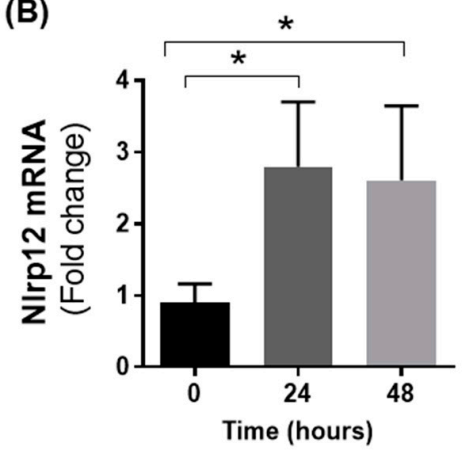

Figure 4. T cell activation increases Nlrp12 mRNA expression. (A) Increased expression of Nlrp12 mRNA in $\mathrm{CD}^{+} \mathrm{T}$ cells activated with anti-CD3 or anti-CD3/CD28 antibodies for $24 \mathrm{~h}$. The higher expression was found in T cells activated with anti-CD3/CD28 antibody compared to $\mathrm{T}$ cell treatment with anti-CD3 or PBS; (B) The expression of Nlrp12 is increased in activated CD4 $4^{+} \mathrm{T}$ cells after 24 and $48 \mathrm{~h}$ activation with anti $(\alpha)-\mathrm{CD} 3 / \mathrm{CD} 28$ antibody; results are presented relative to the expression of Nlrp12 in inactive cells; $n=4,{ }^{*} p<0.05$.

\subsection{Nlrp12 Inhibits Phosphorylation of Akt and NF-kB Signaling in Activated T Cells}

Akt can be activated by TCR signaling in T cell. Accordingly, we studied the early TCR signaling and Akt phosphorylation in T cells downstream of TCR, where Akt is activated by protein kinase $C$ (PKC). For mitogenic stimulation that bypasses the TCR, T cells were treated with the combination of PMA, a permeable specific activator of PKC and calcium ionophore that synergizes with PMA effect in enhancing the activation of PKC [24]. We activated $\mathrm{CD}^{+} \mathrm{T}$ cells by PMA/ionomycin or CD3 cross-linking antibody and evaluated the phosphorylation of Akt and p65 NF- $\mathrm{kB}$ subunit by Western blot. As shown in Figure 5, a significant increase in the phosphorylation of Akt and p65 NF- $\mathrm{kB}$ subunit were found in Nlrp12-/- $\mathrm{CD} 4^{+} \mathrm{T}$ cells compared to WT CD4 ${ }^{+} \mathrm{T}$ cells.

(A)

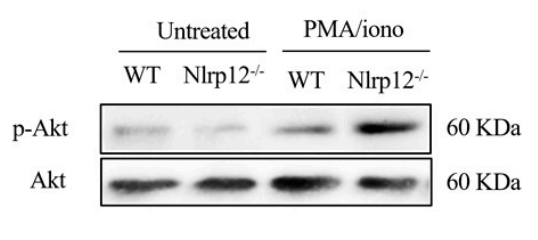

(B)

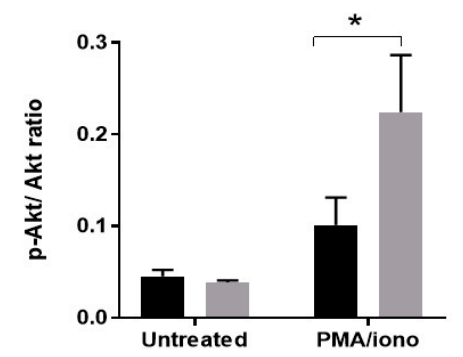

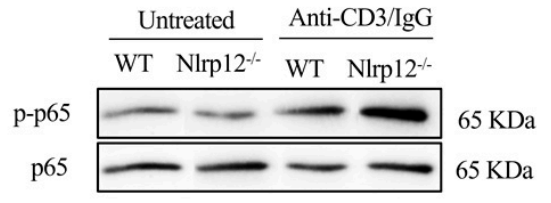

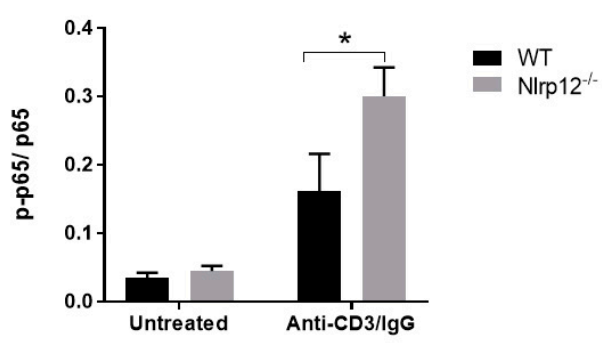

Figure 5. Nlrp12 inhibits phosphorylation of Akt and p65 in $\mathrm{CD}^{+} \mathrm{T}$ cells. The cells were activated either with PMA/ionomycin for 10 min or with cross-linking anti-CD3 antibody (anti-CD3/IgG) for $20 \mathrm{~min}$ at $37^{\circ} \mathrm{C}$. (A) Samples were analyzed by SDS-PAGE and immunoblotting for phospho-Akt (S473) and phospho-p65. Total Akt and p65 expression in the same lysates were used to normalize the expression of phosphorylated molecule between samples; (B) The ratio of phosphorylated to total molecules were compared between WT and Nlrp12-/- cells, $n=3,{ }^{*} p<0.05$. 


\subsection{Nlrp12 Inhibits IL-2 Synthesis but Does Not Modify $\mathrm{Ca}^{2+} /$ Calmodulin-Dependent T Cell Activation}

Since the phosphorylation of NF-kB promotes IL-2 synthesis, we tested whether Nlrp12 inhibit IL-2 production in MOG-specific transgenic CD4 ${ }^{+} \mathrm{T}$ cells. CD4 ${ }^{+} \mathrm{T}$ cells from Nlrp12-/- $2 \mathrm{D} 2$ and WT $2 \mathrm{D} 2$ mice were activated with MOG-pulsed splenocytes and IL-2 expression by CD4 ${ }^{+} \mathrm{T}$ cells was quantified using flow cytometry. Furthermore, to test whether Nlrp12 modifies $\mathrm{Ca}^{2+} /$ calmodulin-dependent $\mathrm{T}$ cell activation, we incubated the $\mathrm{T}$ cells with and $\mathrm{Ca}^{2+} /$ calmodulin inhibitor (cyclosporin) for $24 \mathrm{~h}$ and quantified the percentage of $\mathrm{CD}^{+} \mathrm{IL}^{+} 2^{+} \mathrm{T}$ cells by flow cytometry. As shown in Figure 6, Nlrp12 inhibits IL-2 production by MOG-activated $\mathrm{CD}^{+} \mathrm{T}$ cells, however, it does not interfere with the immunosuppressive activities of cyclosporine, since cyclosporin inhibits IL-2 production in both Nlrp12-/- and WT T cells.

(A)

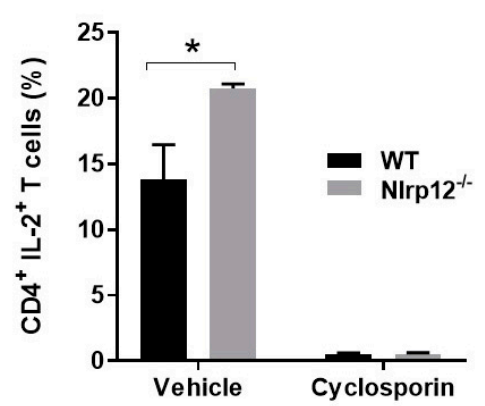

(B)

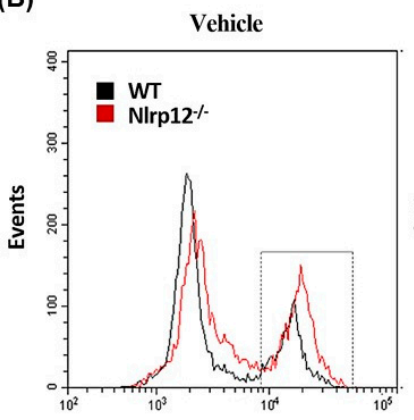

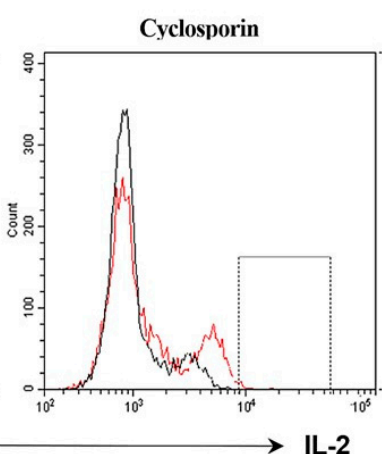

Figure 6. Nlrp12 inhibits IL-2 synthesis by activated T cells. (A) CD4 ${ }^{+}$T cells from WT and Nlrp12-/mice were activated with anti-CD3/CD28 for $24 \mathrm{~h}$ in the presence of cyclosporin or its vehicle (DMSO) for $24 \mathrm{~h}$ and intracellular expression of IL-2 were quantified using flow cytometry; (B) Representative flow cytometric histograms showing the population of IL-2 ${ }^{+}$T cells in vehicle or cyclosporin-treated group, $n=3, * p<0.05$.

\subsection{Nlrp12 Does Not Affect the Phosphorylation of S6 Ribosomal Protein in mTOR Pathway}

IL-2 is known to activate mTOR pathway and to promote cellular growth and clonal expansion of effector T cells [25]. Since we found an increased production of IL-2 and enhanced proliferation of Nlrp12-/- CD4 ${ }^{+}$T cells, we investigate whether Nlrp12 affects mTOR pathway in T cells. We evaluated the phosphorylation of S6 ribosomal protein, which is a critical component of $40 \mathrm{~S}$ ribosomal subunit and sits at the downstream of mTOR pathway. Following $24 \mathrm{~h}$ activation by plate-coated anti-CD3/CD28 antibodies, no significant difference was found between Nlrp12-/- and WT CD4 ${ }^{+} \mathrm{T}$ cells in the levels of phospho-S6, determined by Western blotting and flow cytometry (Figure 7A-C).

(A)

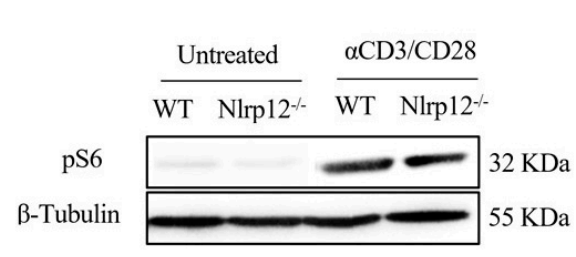

(B)

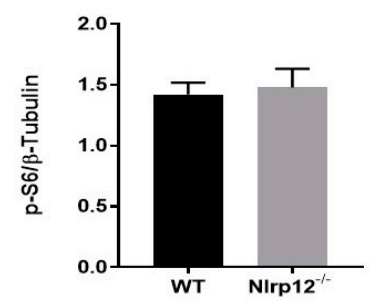

(C)

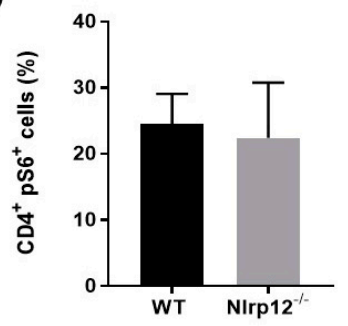

Figure 7. Nlrp12 does not modify mTOR activity. (A) The phosphorylation of S6 ribosomal protein (pS6) as an indicator of mTOR activity was assessed by Western blotting; (B) The ratio of pS6 to $\beta$-Tubulin in WT and Nlrp12-/- CD4 ${ }^{+}$T cells activated with anti-CD3/CD28 for $24 \mathrm{~h}$, as quantified by Western blot, $n=3$; (C) Phospho-flow analysis of pS6 in CD4 ${ }^{+} \mathrm{T}$ cells activated with anti-CD3/CD28 for $24 \mathrm{~h}, n=3$. 


\subsection{Nlrp12-/- 2D2 Mice Are Resistant to the Development of spEAE}

Given the anti-inflammatory role of Nlrp12 in EAE $[19,20]$, we investigated whether Nlrp12-/2D2 mice would develop spEAE. As expected, $6 \%$ of WT 2D2 mice developed EAE spontaneously (Table 1). However, surprisingly, none of Nlrp12-/- 2D2 mice developed spEAE (Table 1). Pathological examination of WT 2D2 spEAE mice revealed marked inflammation associated with infiltration of mononuclear cells to the spinal cord and increased expression of microglia and astrocyte markers (Iba1 and GFAP respectively) (Figure 8). The inflammation was associated with demyelination, as shown in by immunofluorescence staining of myelin basic protein (MBP) (Figure 8). Using flow cytometry, we found a similar percentage of myelin-specific T cells $\left(\mathrm{V} \beta 11^{+}\right)$in the spleens of Nlrp12 ${ }^{-/}$2D2 mice and WT 2D2 mice (Figure 9). However, a high percentage of leukocytes (CD45 high) including $\mathrm{V} \beta 11^{+} \mathrm{T}$ cells infiltrated to the spinal cord of WT 2D2 spEAE compared to healthy mice (Figure 9).

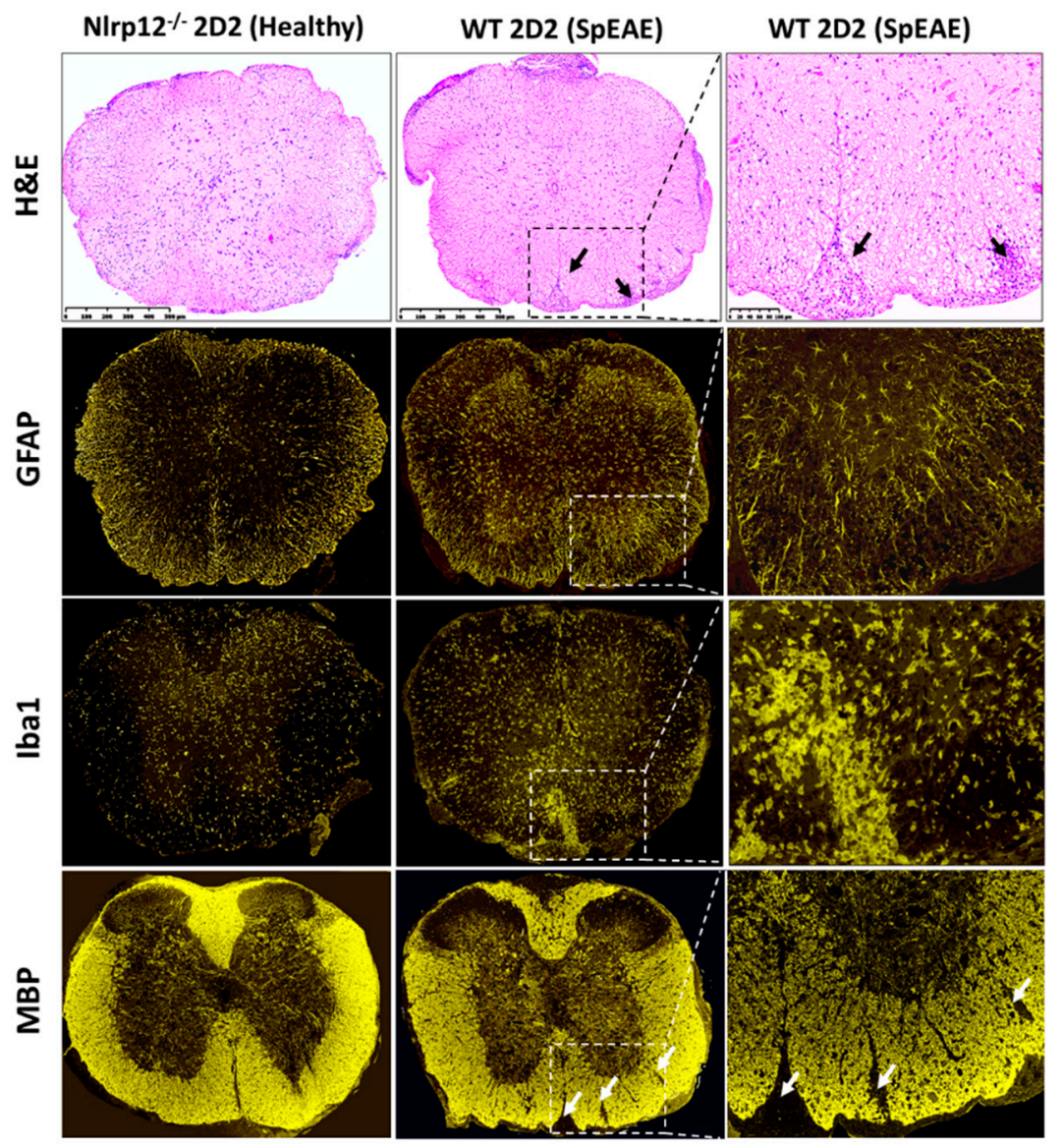

Figure 8. SpEAE in WT 2D2 mice is associated with spinal cord inflammation and demyelination. Representative histopathological examination of the spinal cords from healthy Nlrp12-/- $2 \mathrm{D} 2$ mice and spEAE WT 2D2 mice. H\&E staining reveals an extensive mononuclear cell infiltration to the spinal cord of spEAE mice (shown by black arrows). Immunofluorescent staining of spinal cords from WT 2D2 spEAE shows an increased expression of GFAP (astrocyte marker) and Iba1 (macrophage/microglia marker) mice compared to Nlrp12-/- 2D2 healthy mice. Focal demyelinating lesions (shown by white arrows) are observed in spEAE spinal cords using MBP staining. Similar histopathological features to healthy Nlrp12-/- 2D2 mice were found in healthy WT 2D2 mice (images not shown). 
(A)

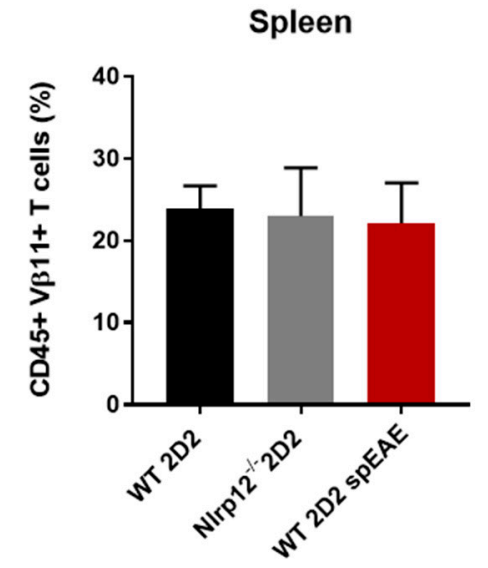

(B)

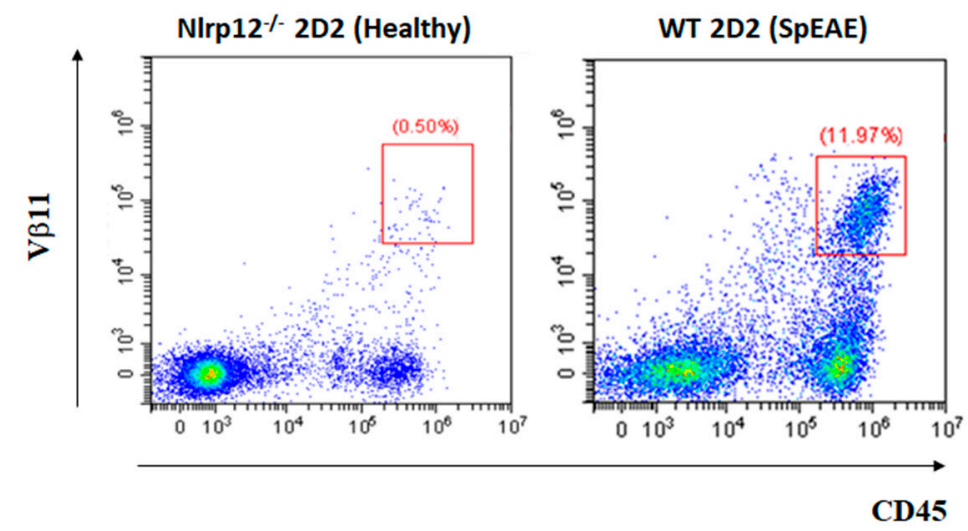

Spinal cord

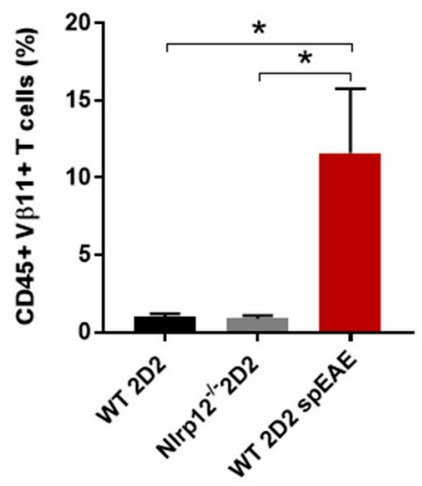

Figure 9. Myelin-specific T cells infiltrate to the spinal cord of spEAE mice. (A) The percentage of $\mathrm{T}$ cells expressing myelin-specific transgenic TCR $\left(\mathrm{V} \beta 11^{+}\right)$were comparable in the spleen of healthy and spEAE mice, however, the percentage of $\mathrm{V} \beta 11^{+} \mathrm{T}$ cells were increased in the spinal cord of spEAE mice compared to WT healthy and Nlrp12-/- healthy mice $(n=6),{ }^{*} p<0.05$; (B) Representative flow cytometry plots of $\mathrm{CD}_{4} 5^{+} \mathrm{V} \beta 11^{+} \mathrm{T}$ cells in the spinal cord of Nlrp12-/- $2 \mathrm{D} 2$ healthy and WT 2D2 spEAE mice.

Table 1. Nlrp12 does not prevent the development of spEAE. None of Nlrp12-/- 2D2 mice developed spEAE, while 6 WT 2D2 mice out of 101 developed spEAE, manifested with ascending paralysis. Nlrp12-/- 2D2 mice were monitored for 16 weeks and no sign of classical EAE was observed.

\begin{tabular}{|c|c|c|c|c|}
\hline Genotype & Total $(n)$ & SpEAE (\%) & Age of Onset (Weeks) & EAE Score \\
\hline WT 2D2 & 101 & 6 & $10.1 \pm 4.7$ & $3.6 \pm 0.5$ \\
\hline Nlrp12-/- 2D2 & 30 & 0 & - & - \\
\hline
\end{tabular}

\section{Discussion}

Early reports showed the expression and anti-inflammatory function of Nlrp12 in innate immune cells of myeloid origin such as DC and macrophages [18,26]. However, a very recent report by Lukens et al. revealed the expression of Nlrp12 in T cells [20]. The current study aimed to investigate the immunoregulatory function of Nlrp12 in T cell-mediated immune response in EAE. Our results suggest that Nlrp12 plays pivotal role in Th1/Th2 balance by inhibiting Th1 peripheral responses in the favor of Th2. We demonstrated that in - lymph nodes of Nlrp12-/- mice, Th1 to Th2 ratio is increased compared to WT mice. This shift, in part, can be explained by significant increases in the production of IFN $\gamma$ by Nlrp12-/- T cells. Interestingly, Nlrp12 does not play a role in the differentiation of naïve T cells but upregulates IL-2 production and proliferation of $\mathrm{CD}^{+} \mathrm{T}$ cells. The effect of Nlrp12 is associated 
with its increased expression and inhibition of major molecular pathways including Akt and NF- $\mathrm{kB}$ in activated T cells.

Previously, we published that Nlrp12-/- mice develop more severe form of EAE than WT mice, which is associated with exacerbated spinal cord inflammation and increased activation of microglia in Nlrp $12^{-/-}$mice compared to WT mice [19]. In the present study, we found an increased Th1 dominant response in lymph nodes of Nlrp12 ${ }^{-/-}$EAE mice, suggesting that Nlrp12 suppresses Th1 activation in the periphery. Interestingly, we did not find any change in the levels of IFN $\gamma$ and IL-4 in the CNS from Nlrp $12^{-/-}$EAE mice compared to WT EAE mice. However, the IFN $\gamma /$ IL-4 ratio significantly decreased in the spinal cord of Nlrp12-/- EAE mice compared to WT EAE mice, which is consistent with Lukens et al. observation of enhanced Th2 response and increased IL-4 production in the CNS of Nlrp12-/- EAE mice [20]. In contrast to Lukens' study where Nlrp12-/- mice developed atypical EAE signs, we found severe classical EAE signs in Nlrp12-/- mice compared to WT mice [19]. Several plausible explanations of these discrepancies were proposed in our recent review [9]. One possibility might be related to the difference in MOG-adjuvant immunization protocols between various labs. In our report, WT and Nlrp12-/- animals were immunized with a total dose of $200 \mu \mathrm{g}$ MOG [19], which is two-fold higher than the immunization dose used by Lukens et al. [20]. Interestingly, a recent study showed that immunization with low or high MOG concentration can modify the patterns of inflammatory cytokines [27]. Their study demonstrates that anti-inflammatory cytokines such as IL-10 and TGF $\beta$ significantly increase in the CNS of EAE animal immunized with $100 \mu \mathrm{g}$ MOG compared to $300 \mu \mathrm{g}$ MOG immunization. Therefore, it is possible that the severe EAE signs in $N l r p 12^{-/-}$mice in our study were driven by lower levels of IL-10 and TGF $\beta$ anti-inflammatory cytokines or by higher levels of other inflammatory cytokines such as Granulocyte-macrophage colony-stimulating factor (GM-CSF) in the CNS [28,29]. Another possible explanation for observing different EAE profiles is the difference in the environmental conditions and different knockout strategies. It was shown that some C57BL/ 6 colonies have acquired a missense mutation in the Nlrp12 gene that can affect neutrophil responses [30]. In another study, genetic ablation of Nlrp12 was found to cause significant changes in microbiota [17]. Nevertheless, these variabilities highlight the complex immunoregulatory nature of Nlrp12 that warrants further investigation.

Given the important role of $\mathrm{T}$ cells in the pathogenesis of EAE, we further investigated whether Nlrp12 controls T cell proliferation and activation in a T cell-intrinsic manner. We found a significant increase of IFN $\gamma$ and IL-4 levels in the supernatant of Nlrp12-/- compared to WT T cells. However, when we measured the levels of intracellular cytokines by flow cytometry, higher percentage of $\mathrm{CD} 4^{+} \mathrm{IFN} \gamma^{+} \mathrm{T}$ cells were found in Nlrp $12^{-/-}$group, while the percentages of CD4 ${ }^{+} \mathrm{IL}^{-} 4^{+} \mathrm{T}$ cells or $\mathrm{CD} 4^{+} \mathrm{IL}-17^{+} \mathrm{T}$ cells did not change between both groups. We addressed this discrepancy with Ki67 staining and our flow cytometry results revealed that activated Nlrp12- $\mathrm{T}$ cells proliferate significantly more than WT T cells, which explains why we found increased production of both IFN $\gamma$ and IL-4 in the supernatant of activated Nlrp12 ${ }^{-/}$T cells. Consistent with our findings, Lukens et al., observed the higher expression of activation markers, enhanced proliferation and elevated secretion of Th1/Th2/Th17 cytokines by Nlrp12 ${ }^{-/-}$T cells compared to WT T cells in vitro [20]. Collectively, these results show that Nlrp12 inhibits the activation of inflammatory T cell subsets including Th1 and Th17.

In the presence of polarizing cytokines, we found no difference between Nlrp12-/- or WT T cells in the expression of Th1- or Th17- associated molecules, suggesting that Nlrp12 does not affect the differentiation of naïve $T$ cells to Th1 or Th17. In a recent study by Cai et al., purified $\mathrm{CD} 4^{+} \mathrm{T}$ cells from Nlrp $12^{-1-}$ or WT mice were activated with anti-CD3 and polarizing cytokines for 6 days. They showed that the differentiation of Nlrp $12^{-/-}$T cells to Th1 or Th17 cells were significantly lower than WT T cells. However, no difference was found between WT and Nlrp12 ${ }^{-/-} \mathrm{T}$ cells in Th2 differentiation [31]. Taken together, it appears that Nlrp12 $2^{-/} \mathrm{T}$ cells respond differently to the environmental stimuli, depending on the type of activating signals, incubation period and polarizing conditions. 
Our results, in agreement with Lukens' study [20], showed that Nlrp12 inhibits T cell activation and proliferation. We found that the expression of Nlrp12 was significantly increased in $\mathrm{T}$ cells following activation by anti-CD3 or anti-CD3/CD28 antibodies. The increased level of Nlrp12 expression remained high even after $48 \mathrm{~h}$ stimulation of T cells, suggesting that Nlrp12 modulates T cell signaling pathways upon TCR stimulation.

Since multiple signaling pathways are involved in $\mathrm{T}$ cell activation and proliferation, we hypothesized that signaling pathways were inhibited by Nlrp12 in activated T cells. It is well-established that TCR activation triggers calcineurin $\left(\mathrm{a} \mathrm{Ca}^{2+} /\right.$ calmodulin-dependent phosphatase), MAPK and NF- $\mathrm{KB}$ signaling pathways, leading to the activation of the nuclear factor of activated $\mathrm{T}$ cell (NFAT), AP1 and NF-kB transcription factors that initiate IL-2 transcription [22]. In this regard, we evaluated the phosphorylation of p65 (NF- $\mathrm{kB}$ subunit) and Akt in activated CD4 ${ }^{+} \mathrm{T}$ cells. Western blot results demonstrated a significant increase in the phosphorylation of p65 in activated Nlrp12-l- $\mathrm{T}$ cells compared to WT T cells, highlighting the inhibitory effect of Nlrp12 on NF-kB signaling pathway (Figure 10). These results are in agreement with previous studies that show Nlrp12 suppresses canonical and non-canonical NF-kB pathways $[16,20,32,33]$.

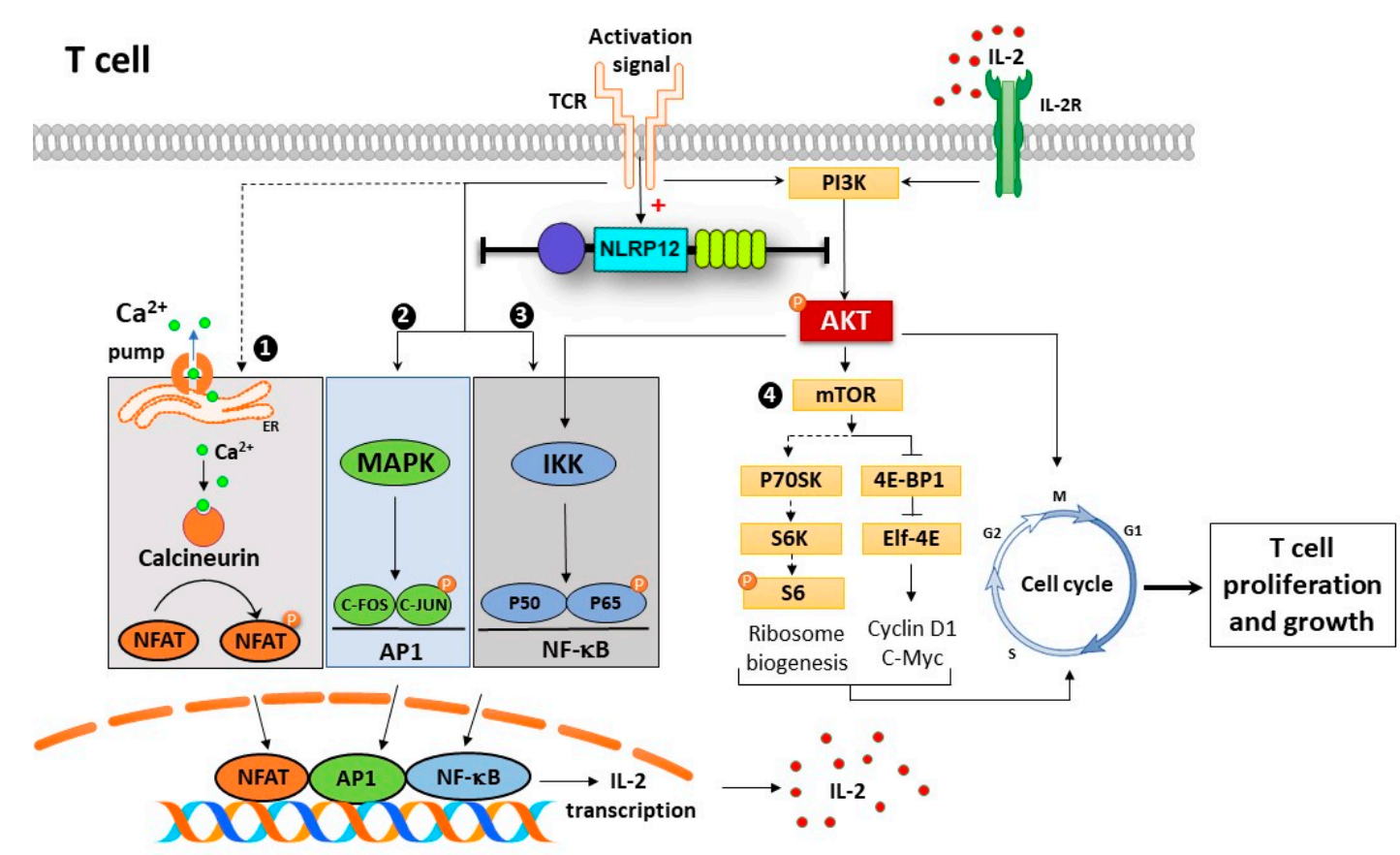

Figure 10. Possible mechanism of action of Nlrp12 in regulating early TCR signaling pathways, $\mathrm{T}$ cell activation and proliferation. Activation signals from TCR activates multiple downstream signaling pathways in T cells, presented as (1) NFAT, (2) NF- KB, (3) MAPK and (4) mTOR pathways. These pathways lead to nuclear translocation of NFAT, NF-KB and AP1 transcription factors and IL-2 transcription. IL-2 binds to its receptor on the cell surface and initiates mTOR pathway. TCR activating signals induce the expression of Nlrp12 that consequently inhibits NF- $\mathrm{BB}$ and MAPK signaling pathways, which suppress IL-2 production. Upstream of NF- $\mathrm{B}$ pathway, Nlrp12 inhibits Akt phosphorylation that controls NF- $\mathrm{kB}$ signaling on one side and mTOR activity and cell cycle progression on the other side. Taken together, Nlrp12 has a broad range of regulatory activity that controls hyper-proliferation and activation of $\mathrm{T}$ cells. The pathways shown in dashed lines are not affected by Nlrp12 including NFAT signaling and mTOR/S6 phosphorylation.

The NF- $\mathrm{KB}$ signaling cascade interacts with several parallel pathways including the signaling cascades initiated by phosphatidylinositol 3-kinase (PI3K) and Akt. We found a significant increase of Akt(Ser 473) phosphorylation in Nlrp12 ${ }^{-1-} \mathrm{T}$ cells compared to WT T cells. These results are supported by a study that demonstrates Nlrp12 negatively regulates Akt signaling pathway in 
affected tumor tissues in colitis model [16]. Interestingly, Akt acts upstream of NF- $\mathrm{kB}$, where the activation of PI3K/Akt signaling pathway leads to phosphorylation and degradation of IKB protein, resulting in nuclear translocation and transcriptional activation of NF- $\mathrm{kB}$ [34]. Taken together, our results demonstrate that Nlrp12 inhibits Akt signaling pathway, which, subsequently, affects downstream pathways including NF-kB pathway. Moreover, phosphorylated Akt blocks the activity of two G1-checkpoint inhibitors, p21 and p27, and promotes cell cycle progression [35]. Collectively, our results suggest that Nlrp12 controls T cell proliferation and cytokine production by inhibiting the activation of Akt, that, in turn, affects several downstream effectors (Figure 10).

One of the signaling pathways downstream of Akt phosphorylation is mTOR pathway, which induces protein synthesis and cell growth by regulating ribosomal p70S6 kinase 1 (S6K1) and eukaryotic translation factor 4E-binding protein 1 (4EBP1). S6K1 phosphorylates and activates S6, a ribosomal subunit involved in initiating protein synthesis machinery. Using western blotting and flow cytometry, we found no difference between Nlrp12-1- T cells and WT T cells in the level of S6 phosphorylation. Therefore, it is possible that Nlrp12 regulates protein synthesis and cell growth via modulating the activity of 4EBP1 (Figure 10). Further investigation is warranted to uncover the regulatory mechanism of Nlrp12 on mTOR signaling pathway.

The results of this study and previous publications suggest that Nlrp12 inhibits NF-KB and MAPK signaling pathways in activated T cells $[20,36]$. The transcription of IL-2 gene is regulated by NF- $\mathrm{KB}$, MAPK and $\mathrm{Ca}^{2+} /$ calmodulin-dependent pathways [37,38]. Accordingly, we hypothesized that Nlrp12 inhibits IL-2 production by activated $\mathrm{CD} 4^{+} \mathrm{T}$ cells. Flow cytometry data revealed a higher percentage of $\mathrm{CD}^{+} \mathrm{IL}^{2} 2^{+} \mathrm{T}$ cells in activated Nlrp $12^{-/-} \mathrm{CD} 4^{+}$cells compared to $\mathrm{WT} \mathrm{CD} 4^{+} \mathrm{T}$ cells, suggesting that Nlrp12 suppresses IL-2 production by activated T cells. Incubation with cyclosporin inhibited IL-2 production by both Nlrp12-/- and WT T cells, indicating that lack of Nlrp12 does not affect $\mathrm{Ca}^{2+} /$ calmodulin signaling pathway in $\mathrm{T}$ cells.

Our in vitro findings, together with results obtained from in vivo EAE model, support the idea that Nlrp12 inhibits $\mathrm{T}$ cell responses. In $2 \mathrm{D} 2$ mice, due to the presence of many MOG-reactive $\mathrm{T}$ cells, about $4-14 \%$ of mice developed spEAE [39,40]. In $2 \mathrm{D} 2$ mice, the percentage of $\mathrm{V} \beta 11^{+} \mathrm{T}$ cells in the spleen were the same between healthy and spEAE animals, showing that our affected and non-affected animals had similar percentage of MOG-reactive T cells. However, a high percentage of MOG-reactive T cells infiltrated to the spinal cord of WT 2D2 spEAE mice, which confirms the presence of autoreactive T cells in inflamed spinal cord. The healthy Nlrp12-/- $2 \mathrm{D} 2$ animals have only a few $\mathrm{V} \beta 11^{+} \mathrm{T}$ cells in the spinal cord and do not contain pathology. The fact that none of Nlrp12-/- $2 \mathrm{D} 2$ mice develop disease suggests that Nlrp12 does not inhibit the development of spEAE and even can serve as contributing factor in the pathology of EAE. Due to slow rate of breeding of Nlrp12-/- $2 \mathrm{D} 2$ mice (unpublished observation), these conclusions are based on the observation of thirty Nlrp12-/- $2 \mathrm{D} 2$ mice. Interestingly, previous studies report that in induced EAE, Nlrp12 can prevent [19] or promote [20] CNS inflammation. To explain the observed controversy, we propose a dual immunoregulatory function for Nlrp12, in which Nlrp12 can act as an inflammatory or anti-inflammatory molecule, depending on the type and severity of immunological challenge. The hypothetical model of Nlrp12 immunoregulation is shown in Figure 11.

The bifunctional nature of Nlrp12 has been previously reported in several studies $[16,19,20,31,36,41,42]$. Early in vitro studies suggest that Nlrp12 is an inflammatory NLR that interacts with ASC to form inflammasome [43]. Recent reports also support this idea and show that Nlrp12 activates inflammasome in Yersinia Pestis and Plasmodium infections [42,44]. Moreover, several behavioral outcomes are similar between $\mathrm{ASC}^{-/-}$and Nlrp12-/- mice [45]. On the other hand, there are studies that classify Nlrp12 as an anti-inflammatory molecule and the inhibitor of NF- KB signaling pathway $[16,18,32,46]$. In this regard, Nlrp $12^{-/-}$mice were shown to be highly susceptible to inflammatory diseases of intestine such as experimental colitis and colon cancer [16,18]. Taken together, these findings support the dual immunoregulatory nature of Nlrp12, that may vary in a cell-specific or stimulus-specific manner. 


\begin{tabular}{|c|ccc|}
\hline $\begin{array}{c}\text { Immunological } \\
\text { challenge }\end{array}$ & Low & Medium & High \\
\hline Challenge Type & $\begin{array}{c}\text { No Immunization } \\
\text { (spEAE) }\end{array}$ & $\begin{array}{c}\text { Immunization } \\
\text { (low dose) }\end{array}$ & $\begin{array}{c}\text { Immunization } \\
\text { (High dose) }\end{array}$ \\
\hline $\begin{array}{c}\text { Clinical sign of EAE } \\
\text { in NIrp12\% mice }\end{array}$ & None & Mild & Severe \\
\hline $\begin{array}{c}\text { Immunoregulatory } \\
\text { Activity of NIrp12 }\end{array}$ & Inflammatory & $\begin{array}{c}\text { Inflammatory/ } \\
\text { anti-inflammatory }\end{array}$ & Anti-inflammatory \\
\hline
\end{tabular}

Figure 11. Dual immunoregulatory function of Nlrp12 in EAE. The severity of immunological challenge, ranging from low to high, can influence the regulatory function of Nlrp12 in EAE. In this model, when there is no MOG/CFA immunization, myelin-specific T cells face a low level of challenge. In this case, Nlrp12 plays an inflammatory role, which explains why WT 2D2 mice developed spEAE and Nlrp12-/- 2D2 mice were resistant to spEAE. On the other hand, with MOG/CFA immunization, T cells encounter immunological challenge that may vary from medium to high levels. In mild challenge, perhaps with lower dose of MOG-CFA immunization, Nlrp12 is a bifunctional molecule, acting as an inflammatory or anti-inflammatory molecule. In this condition, EAE mice developed mild EAE signs, mostly atypical symptoms such as ataxia [20]. When MOG/CFA immunization provides high levels of immunological challenge, Nlrp12 acts as an anti-inflammatory molecule, inhibiting severe signs of classical EAE [19]. Given the fact that Nlrp12 ligand is still unknown, what exactly tunes Nlrp12 response as a pro-inflammatory or anti-inflammatory molecules, needs further investigation.

In conclusion, the present study provides new insight into the immunoregulatory role of Nlrp12 in T cell-mediated CNS inflammation, triggered by different modes of immunological challenges (induced EAE and spEAE). We demonstrated for the first time that Nlrp12 inhibits early TCR signaling pathways. In this way, Nlrp12 plays critical roles in balancing $\mathrm{T}$ cell response to control overt activation and maintain cellular homeostasis. Indeed, the fine-tuned triggering of Nlrp12 by different immunological challenges determine whether the outcome of the challenge would be an inflammatory or anti-inflammatory response. Factors determining the immunoregulatory function of Nlrp12 remain to be determined.

Supplementary Materials: The following are available online at http:/ /www.mdpi.com/2073-4409/7/9/119/s1, Figure S1: NLRP12 genotyping of a Nlrp12 ${ }^{--}$2D2 mouse and a WT 2D2 mouse. DNA was obtained from ear samples, Figure S2: Clinical score of induced EAE in Nlrp12 $2^{--}$mice compared to WT mice.

Author Contributions: M.G., A.A. and D.G. designed the study and the experiments; M.G. performed the experiments, statistical analysis and wrote the manuscript. S.M. and C.S. monitored the animals, genotyped the mice, dissected the tissues and reviewed the manuscript. T.M.M. immunized mice for EAE and collected the tissues. M.G., A.A. and D.G. contributed to the conceptual reading and critical editing of the manuscript. All authors read and approved the manuscript.

Funding: This research was funded by scholarships from the MS Society of Canada, Fonds de Recherche du Québec-Santé (FRQS) and Association de la sclérose en plaques de l’Estrie (ASPE) to M.G.

Conflicts of Interest: The authors declare no conflict of interest.

\section{References}

1. Weissert, R. The immune pathogenesis of multiple sclerosis. J. Neuroimmune Pharmacol. 2013, 8, 857-866. [CrossRef] [PubMed]

2. Kaskow, B.J.; Baecher-Allan, C. Effector T cells in multiple sclerosis. Cold Spring Harb. Perspect. Med. 2018, 8, a029025. [CrossRef] [PubMed]

3. Reich, D.S.; Lucchinetti, C.F.; Calabresi, P.A. Multiple sclerosis. N. Engl. J. Med. 2018, 378, 169-180. [CrossRef] [PubMed]

4. Broux, B.; Stinissen, P.; Hellings, N. Which immune cells matter? The immunopathogenesis of multiple sclerosis. Crit. Rev. Immunol. 2013, 33, 283-306. [CrossRef] [PubMed] 
5. Chitnis, T. The role of CD4 T cells in the pathogenesis of multiple sclerosis. Int. Rev. Neurobiol. 2007, 79, 43-72. [PubMed]

6. Luckheeram, R.V.; Zhou, R.; Verma, A.D.; Xia, B. Cd4 ${ }^{+}$T cells: Differentiation and functions. Clin. Dev. Immunol. 2012, 2012, 925135. [CrossRef] [PubMed]

7. Iwakura, Y.; Nakae, S.; Saijo, S.; Ishigame, H. The roles of il-17a in inflammatory immune responses and host defense against pathogens. Immunol. Rev. 2008, 226, 57-79. [CrossRef] [PubMed]

8. Palm, N.W.; Medzhitov, R. Pattern recognition receptors and control of adaptive immunity. Immunol. Rev. 2009, 227, 221-233. [CrossRef] [PubMed]

9. Gharagozloo, M.; Gris, K.V.; Mahvelati, T.; Amrani, A.; Lukens, J.R.; Gris, D. Nlr-dependent regulation of inflammation in multiple sclerosis- dependent regulation of inflammation in multiple sclerosis. Front. Immunol. 2017, 8, 2012. [CrossRef] [PubMed]

10. Reith, W.; LeibundGut-Landmann, S.; Waldburger, J.M. Regulation of MHC class II gene expression by the class II transactivator. Nat. Rev. Immunol. 2005, 5, 793-806. [CrossRef] [PubMed]

11. Neerincx, A.; Jakobshagen, K.; Utermohlen, O.; Buning, H.; Steimle, V.; Kufer, T.A. The N-terminal domain of Nlrc5 confers transcriptional activity for MHC class I and II gene expression. J. Immunol. 2014, 193, 3090-3100. [CrossRef] [PubMed]

12. Meissner, T.B.; Li, A.; Kobayashi, K.S. Nlrc5: A newly discovered MHC class I transactivator (CITA). Microbes Infect. 2012, 14, 477-484. [CrossRef] [PubMed]

13. Bruchard, M.; Rebé, C.; Derangère, V.; Togbé, D.; Ryffel, B.; Boidot, R.; Humblin, E.; Hamman, A.; Chalmin, F.; Berger, H.; et al. The receptor Nlrp3 is a transcriptional regulator of Th2 differentiation. Nat. Immunol. 2015, 16, 859. [CrossRef] [PubMed]

14. Gris, D.; Ye, Z.; Iocca, H.A.; Wen, H.; Craven, R.R.; Gris, P.; Huang, M.; Schneider, M.; Miller, S.D.; Ting, J.P. Nlrp3 plays a critical role in the development of experimental autoimmune encephalomyelitis by mediating Th1 and Th17 responses. J. Immunol. 2010, 185, 974-981. [CrossRef] [PubMed]

15. Sun, S.-C. Non-canonical NF-kB signaling pathway. Cell Res. 2011, 21, 71-85. [CrossRef] [PubMed]

16. Allen, I.C.; Wilson, J.E.; Schneider, M.; Lich, J.D.; Roberts, R.A.; Arthur, J.C.; Woodford, R.-M.T.; Davis, B.K.; Uronis, J.M.; Herfarth, H.H.; et al. Nlrp12 suppresses colon inflammation and tumorigenesis through the negative regulation of non-canonical NF-kB signaling and map kinase activation. Immunity 2012, 36, 742-754. [CrossRef] [PubMed]

17. Chen, L.; Wilson, J.E.; Koenigsknecht, M.J.; Chou, W.C.; Montgomery, S.A.; Truax, A.D.; Brickey, W.J.; Packey, C.D.; Maharshak, N.; Matsushima, G.K.; et al. Nlrp12 attenuates colon inflammation by maintaining colonic microbial diversity and promoting protective commensal bacterial growth. Nat. Immunol. 2017, 18, 541-551. [CrossRef] [PubMed]

18. Zaki, M.H.; Vogel, P.; Malireddi, R.K.; Body-Malapel, M.; Anand, P.K.; Bertin, J.; Green, D.R.; Lamkanfi, M.; Kanneganti, T.D. The nod-like receptor Nlrp12 attenuates colon inflammation and tumorigenesis. Cancer Cell 2011, 20, 649-660. [CrossRef] [PubMed]

19. Gharagozloo, M.; Mahvelati, T.M.; Imbeault, E.; Gris, P.; Zerif, E.; Bobbala, D.; Ilangumaran, S.; Amrani, A.; Gris, D. The nod-like receptor, Nlrp12, plays an anti-inflammatory role in experimental autoimmune encephalomyelitis. J. Neuroinflamm. 2015, 12, 198. [CrossRef] [PubMed]

20. Lukens, J.R.; Gurung, P.; Shaw, P.J.; Barr, M.J.; Zaki, M.H.; Brown, S.A.; Vogel, P.; Chi, H.; Kanneganti, T.D. The Nlrp12 sensor negatively regulates autoinflammatory disease by modulating interleukin-4 production in T cells. Immunity 2015, 42, 654-664. [CrossRef] [PubMed]

21. Schmittgen, T.D.; Livak, K.J. Analyzing real-time PCR data by the comparative $C_{\mathrm{T}}$ method. Nat. Protoc. 2008, 3, 1101-1108. [CrossRef] [PubMed]

22. Smith-Garvin, J.E.; Koretzky, G.A.; Jordan, M.S. T cell activation. Ann. Rev. Immunol. 2009, 27, 591-619. [CrossRef] [PubMed]

23. Soares, A.; Govender, L.; Hughes, J.; Mavakla, W.; De Kock, M.; Barnard, C.; Pienaar, B.; Janse van Rensburg, E.; Jacobs, G.; Khomba, G.; et al. Novel application of ki67 to quantify antigen-specific in vitro lymphoproliferation. J. Immunol. Methods 2010, 362, 43-50. [CrossRef] [PubMed]

24. Chatila, T.; Silverman, L.; Miller, R.; Geha, R. Mechanisms of T cell activation by the calcium ionophore ionomycin. J. Immunol. 1989, 143, 1283-1289. [PubMed]

25. Brennan, P.; Babbage, J.W.; Burgering, B.M.T.; Groner, B.; Reif, K.; Cantrell, D.A. Phosphatidylinositol 3-kinase couples the interleukin-2 receptor to the cell cycle regulator E2F. Immunity 1997, 7, 679-689. [CrossRef] 
26. Arthur, J.C.; Lich, J.D.; Wilson, J.E.; Ye, Z.; Allen, I.C.; Gris, D.; Schneider, M.; Roney, K.E.; O'Connor, B.P.; Moore, C.B.; et al. Nlrp12 controls dendritic and myeloid cell migration to affect contact hypersensitivity. J. Immunol. 2010, 185, 4515-4519. [CrossRef] [PubMed]

27. Dias, A.T.; De Castro, S.B.; Alves, C.C.; Mesquita, F.P.; De Figueiredo, N.S.; Evangelista, M.G.; Castanon, M.C.; Juliano, M.A.; Ferreira, A.P. Different $\mathrm{MOG}_{35-55}$ concentrations induce distinguishable inflammation through early regulatory response by IL-10 and TGF- $\beta$ in mice CNS despite unchanged clinical course. Cell. Immunol. 2015, 293, 87-94. [CrossRef] [PubMed]

28. Palle, P.; Monaghan, K.L.; Milne, S.M.; Wan, E.C.K. Cytokine signaling in multiple sclerosis and its therapeutic applications. Med. Sci. 2017, 5, E0023. [CrossRef] [PubMed]

29. Kroenke, M.A.; Chensue, S.W.; Segal, B.M. EAE mediated by a non-IFN- $\gamma /$ non-IL-17 pathway. Eur. J. Immunol. 2010, 40, 2340-2348. [CrossRef] [PubMed]

30. Ulland, T.K.; Jain, N.; Hornick, E.E.; Elliott, E.I.; Clay, G.M.; Sadler, J.J.; Mills, K.A.; Janowski, A.M.; Volk, A.P.; Wang, K.; et al. Nlrp12 mutation causes C57BL/6J strain-specific defect in neutrophil recruitment. Nat. Commun. 2016, 7, 13180. [CrossRef] [PubMed]

31. Cai, S.; Batra, S.; Del Piero, F.; Jeyaseelan, S. Nlrp12 modulates host defense through IL-17A-CXCL1 axis. Mucosal Immunol. 2016, 9, 503-514. [CrossRef] [PubMed]

32. Lich, J.D.; Williams, K.L.; Moore, C.B.; Arthur, J.C.; Davis, B.K.; Taxman, D.J.; Ting, J.P.-Y. Cutting edge: Monarch-1 suppresses non-canonical NF- $\mathrm{kB}$ activation and p52-dependent chemokine expression in monocytes. J. Immunol. 2007, 178, 1256-1260. [CrossRef] [PubMed]

33. Williams, K.L.; Lich, J.D.; Duncan, J.A.; Reed, W.; Rallabhandi, P.; Moore, C.; Kurtz, S.; Coffield, V.M.; Accavitti-Loper, M.A.; Su, L.; et al. The CATERPILLER protein monarch-1 is an antagonist of toll-like receptor-, tumor necrosis factor $\alpha$ - and mycobacterium tuberculosis-induced pro-inflammatory signals. J. Biol. Chem. 2005, 280, 39914-39924. [CrossRef] [PubMed]

34. Ozes, O.N.; Mayo, L.D.; Gustin, J.A.; Pfeffer, S.R.; Pfeffer, L.M.; Donner, D.B. NF-kB activation by tumour necrosis factor requires the Akt serine-threonine kinase. Nature 1999, 401, 82-85. [CrossRef] [PubMed]

35. Abukhdeir, A.M.; Park, B.H. P21 and p27: Roles in carcinogenesis and drug resistance. Expert Rev. Mol. Med. 2008, 10, e19. [CrossRef] [PubMed]

36. Silveira, T.N.; Gomes, M.T.R.; Oliveira, L.S.; Campos, P.C.; Machado, G.G.; Oliveira, S.C. Nlrp12 negatively regulates proinflammatory cytokine production and host defense against brucella abortus. Eur. J. Immunol. 2017, 47, 51-59. [CrossRef] [PubMed]

37. Enderby, C.; Keller, C.A. An overview of immunosuppression in solid organ transplantation. Am. J. Manag. Care 2015, 21, s12-s23. [PubMed]

38. Halloran, P.F. Immunosuppressive drugs for kidney transplantation. N. Engl. J. Med. 2004, 351, $2715-2729$. [CrossRef] [PubMed]

39. Bettelli, E.; Pagany, M.; Weiner, H.L.; Linington, C.; Sobel, R.A.; Kuchroo, V.K. Myelin oligodendrocyte glycoprotein-specific $\mathrm{T}$ cell receptor transgenic mice develop spontaneous autoimmune optic neuritis. J. Exp. Med. 2003, 197, 1073-1081. [CrossRef] [PubMed]

40. Lafaille, J.J.; Nagashima, K.; Katsuki, M.; Tonegawa, S. High incidence of spontaneous autoimmune encephalomyelitis in immunodeficient anti-myelin basic protein T cell receptor transgenic mice. Cell 1994, 78, 399-408. [CrossRef]

41. Allen, I.C.; McElvania-TeKippe, E.; Wilson, J.E.; Lich, J.D.; Arthur, J.C.; Sullivan, J.T.; Braunstein, M.; Ting, J.P. Characterization of Nlrp12 during the in vivo host immune response to klebsiella pneumoniae and mycobacterium tuberculosis. PLoS ONE 2013, 8, e60842. [CrossRef]

42. Vladimer, G.I.; Weng, D.; Paquette, S.W.; Vanaja, S.K.; Rathinam, V.A.; Aune, M.H.; Conlon, J.E.; Burbage, J.J.; Proulx, M.K.; Liu, Q.; et al. The Nlrp12 inflammasome recognizes yersinia pestis. Immunity 2012, 37, 96-107. [CrossRef] [PubMed]

43. Wang, L.; Manji, G.A.; Grenier, J.M.; Al-Garawi, A.; Merriam, S.; Lora, J.M.; Geddes, B.J.; Briskin, M.; DiStefano, P.S.; Bertin, J. PYPAF7, a novel PYRIN-containing Apaf1-like protein that regulates activation of NF-кB and caspase-1-dependent cytokine processing. J. Biol. Chem. 2002, 277, 29874-29880. [CrossRef] [PubMed] 
44. Ataide, M.A.; Andrade, W.A.; Zamboni, D.S.; Wang, D.; Do Carmo Souza, M.; Franklin, B.S.; Elian, S.; Martins, F.S.; Pereira, D.; Reed, G. Malaria-induced Nlrp12/Nlrp3-dependent caspase-1 activation mediates inflammation and hypersensitivity to bacterial superinfection. PLoS Pathog. 2014, 10, e1003885. [CrossRef] [PubMed]

45. Gris, K.V.; Yamamoto, K.; Gharagozloo, M.; Mahmoud, S.; Simard, C.; Gris, P.; Gris, D. Exhaustive behavioral profile assay to detect genotype differences between wild-type, inflammasome-deficient and Nlrp12 knock-out mice. AIMS Med. Sci. 2018, 5, 238-251. [CrossRef]

46. Conti, B.J.; Davis, B.K.; Zhang, J.; O'Connor, W., Jr.; Williams, K.L.; Ting, J.P. CATERPILLER 16.2 (CLR16.2), a novel NBD/LRR family member that negatively regulates T cell function. J. Biol. Chem. 2005, 280, 18375-18385. [CrossRef] [PubMed]

(C) 2018 by the authors. Licensee MDPI, Basel, Switzerland. This article is an open access article distributed under the terms and conditions of the Creative Commons Attribution (CC BY) license (http:/ / creativecommons.org/licenses/by/4.0/). 